\title{
Estimated Budget Impact of Increased Use of Mirabegron, A Novel Treatment for Overactive Bladder
}

\author{
Sinem Perk, PhD; Ronald C. Wielage, MPH; Noll L. Campbell, PharmD; Timothy M. Klein, BS; \\ Anthony Perkins, MS; Linda M. Posta, PharmD, MBA; Thomas Yuran, PharmD; \\ Robert W. Klein, MS; and Daniel B. Ng, PharmD, MBA
}

\begin{abstract}
BACKGROUND: Oral pharmacological treatment for overactive bladder (OAB) consists of antimuscarinics and the beta-3 adrenergic agonist mirabegron. Antimuscarinic adverse events (AEs) such as dry mouth, constipation, and blurry vision can result in frequent treatment discontinuation rates, leaving part of the $\mathrm{OAB}$ population untreated. Antimuscarinics also contribute to a patient's anticholinergic cognitive burden (ACB), so the Beers Criteria recommends cautious use of antimuscarinics in elderly patients who take multiple anticholinergic medications or have cognitive impairment. Since mirabegron does not affect the cholinergic pathways, it is unlikely to contribute to a patient's ACB.
\end{abstract}

OBJECTIVE: To estimate the health care costs associated with the pharmacological treatment of $O A B$ with mirabegron and antimuscarinics from U.S. commercial payer and Medicare Advantage perspectives, using a budget impact model.

METHODS: For this budget impact model, 2 analyses were performed. The primary analysis estimated the budgetary impact of increasing the use of mirabegron in a closed patient cohort treated with oral pharmacological treatments. The secondary analysis modeled the economic impact in an open cohort by allowing untreated patients to begin treatment with mirabegron after potential contraindication, intolerance, or lack of effectiveness of antimuscarinics. The analyses were performed over a 3-year time horizon. The economic impact of increased mirabegron use was quantified using direct medical costs, including prescription costs and health resource utilization (HRU) costs. Costs of comorbidities included pharmacy and medical costs of treating $O A B-$ related urinary tract infections (UTI), skin rashes, and depression. An analysis of a large single-site integrated health network database was commissioned to quantify ACB-related HRU in terms of the increases in yearly outpatient and emergency department visits. Based on this analysis, the model associated each unit increase in ACB score with increased HRU and probability of mild cognitive impairment. Clinical outcomes of increased use of mirabegron were presented as the number of AEs and comorbidity episodes that could be avoided. One-way sensitivity analyses were performed to quantify the expected budget impact over the range of uncertainty for the key input variables.

RESULTS: Primary analysis calculated the impact of increasing the use of mirabegron from $4.5 \%$ to $5.3 \%, 7.1 \%$, and $9.4 \%$ in years 1,2 , and 3 , respectively, among oral pharmacological $O A B$ treatments that included generic and branded antimuscarinics: oxybutynin, tolterodine, trospium, darifenacin, fesoterodine, and solifenacin. For a 1 million-member U.S. commercial payer plan, the total prescription costs increased, and the total medical costs decreased during the 3-year time horizon, yielding increases of $\$ 0.005, \$ 0.016$, and $\$ 0.031$ from current per member per month (PMPM) costs and $\$ 0.90, \$ 2.92$, and $\$ 5.53$ from current per treated member per month (PTMPM) costs, an average of less than $2 \%$ of current $0 A B$ treatment costs. For the Medicare Advantage plan, the resulting incremental PMPM costs were $\$ 0.010, \$ 0.034$, and $\$ 0.065$, and the incremental PTMPM costs were $\$ 0.93, \$ 3.04$, and $\$ 5.76$; all were less than $4 \%$ of the current cost. The secondary analysis estimated the budgetary effects of reducing the untreated population by $1 \%$ annually by initiating treatment with mirabegron. For a commercial payer, this resulted in PMPM cost increases of $\$ 0.156, \$ 0.311$, and $\$ 0.467$ from the current value, while the incremental PTMPM cost increased by $\$ 6.17, \$ 11.67$, and $\$ 16.61$. For the Medicare Advantage plan, the incremental increases in PMPM costs were $\$ 0.277, \$ 0.553$, and $\$ 0.830$, and in PTMPM costs were $\$ 6.42, \$ 12.15$, and $\$ 17.29$. Clinically, treating more $O A B$ patients resulted in fewer $O A B-$ related comorbidities from both health plan perspectives, since most events associated with nontreatment could be avoided. In the Medicare Advantage population of the secondary analysis, the total numbers of avoided events were predicted as 452 UTIs, 2,598 depression diagnoses, and 3,020 skin rashes during the time horizon of the model.

CONCLUSIONS: Mirabegron addresses an unmet need for therapy for certain $O A B$ patients, for whom antimuscarinics are not recommended because of a risk of cognitive impairment and who are intolerant to the anticholinergic AEs. Using mirabegron involves moderate additional economic cost to a commercial or Medicare Advantage health plan for which medical cost savings can offset a substantial part of increased pharmacy costs.

J Manag Care Spec Pharm. 2016;22(9):1072-86

Copyright $\odot 2016$, Academy of Managed Care Pharmacy. All rights reserved.

\section{What is already known about this subject}

Standard oral pharmacological treatment for overactive bladder (OAB) consists of antimuscarinics, which increase a patient's anticholinergic cognitive burden (ACB) and probability of mild cognitive impairment and also cause anticholinergic adverse events, which result in low persistence.

The Beers Criteria recommends that antimuscarinics be avoided in the elderly population who take multiple medications, experience chronic constipation, or have cognitive impairment including dementia

Mirabegron, a beta-3 adrenoceptor agonist, is a novel treatment for $\mathrm{OAB}$ with a different mechanism of action, is believed not to contribute to a patient's ACB, and has early evidence of improved persistence 


\section{What this study adds}

Budgetary and clinical impacts of increased use of mirabegron were evaluated for a commercial payer and Medicare Advantage by switching treatment from antimuscarinics to mirabegron and expanding the treated population by initiating mirabegron treatment in untreated patients.

Using retrospective data from a large health care system, a linear regression model established the association between increased health care resource utilization per 1-unit increase in ACB in the elderly population.

Primary analysis estimated increases in per treated member per month (PTMPM) costs of an average of less than 2\% of current $\mathrm{OAB}$ treatment costs for commercial payers and $4 \%$ for Medicare Advantage. Secondary analysis estimated increases in PTMPM costs with an average of less than $6.5 \%$ for Medicare Advantage and an average of less than $6 \%$ for commercial payers.

$\mathrm{O}$ veractive bladder $(\mathrm{OAB})$ is a syndrome defined as urinary urgency, usually with urinary frequency and nocturia, with or without urge urinary incontinence, in the absence of urinary tract infection or other obvious pathology. ${ }^{1,2}$ Prevalence of OAB increases with age and is similar among men and women. ${ }^{3}$

First-line treatment for $\mathrm{OAB}$ is behavioral therapies that may be combined with pharmacological management and is followed with oral antimuscarinics or beta-3 adrenoceptor agonists as second-line therapy. ${ }^{3}$ However, use of antimuscarinics is limited in certain patient populations because of contraindications or intolerance to their anticholinergic adverse events (AEs). Antimuscarinics increase the anticholinergic cognitive burden (ACB) of patients and have been listed in the 2012 and 2015 Beers Lists as having strong anticholinergic properties affecting the central nervous system muscarinic receptors. ${ }^{4-6}$ The Beers Criteria for potentially inappropriate medication use in older adults informs health care professionals about the safety of prescribing drugs for older adults and has recommended that anticholinergics be avoided in the elderly population who take multiple medications or have cognitive impairment including dementia.,

The cost of OAB in the United States was estimated as $\$ 65.9$ billion in 2007 and is predicted to reach $\$ 82.6$ billion in 2020, with much of the U.S. payer costs resulting from OAB-related comorbidities. ${ }^{7-9} \mathrm{OAB}$ patients have reported increased rates of urinary tract infections (UTIs), skin conditions such as rashes and infections, sleep disturbances due to nocturia and depression, and more physician visits than those without OAB ${ }^{10-13}$ In addition, untreated $\mathrm{OAB}$ has been found to be a strong predictor of increased health care costs. ${ }^{14,15}$
Mirabegron is a novel agent that was approved in the United States for OAB treatment in 2012, with similar treatment effects as antimuscarinics and early evidence of improved tolerability and treatment persistence. ${ }^{16,17}$ An important distinction between mirabegron and antimuscarinic treatments is that mirabegron is a beta-3 adrenergic agonist that does not have the anticholinergic AEs associated with the poor persistence rates of antimuscarinics and does not contribute to a patient's ACB. ${ }^{13,14,18,19}$ Therefore, mirabegron is a viable option for OAB treatment, addressing a need for therapy in $\mathrm{OAB}$ populations where the use of antimuscarinics is undesirable.

A budget impact model (BIM) was built to study the economic and clinical impact of increased use of mirabegron for the treatment of $\mathrm{OAB}$ from U.S. commercial payer and Medicare Advantage perspectives. A primary analysis quantified the impact of increased mirabegron use as patients switched from antimuscarinics to mirabegron. A secondary analysis modeled the effect of increasing the number of treated $O A B$ patients by initiating mirabegron treatment. Many of these previously untreated patients had a drug-drug or drugdisease contraindication or were intolerant to antimuscarinics.

\section{Methods}

\section{OAB Population}

The National Overactive Bladder Evaluation (NOBLE) study estimated the prevalence of $\mathrm{OAB}$ in the United States as 16.5\%, with similar rates in men (16\%) and women $(16.9 \%),{ }^{20}$ which corresponded to the approximate 34 million people with $\mathrm{OAB}$ symptoms in 2007.20,21 The Epidemiology of Lower Urinary Tract Symptoms (EpiLUTS) study assessed OAB prevalence among adults aged 40 years and older as 23\%, yielding 29.8 million (2005 census figures) adults having bothersome OAB symptoms. ${ }^{22}$

In this BIM, the U.S. OAB population distribution was calculated starting with U.S. Census Bureau population age and gender distribution, ${ }^{23}$ bifurcating to strata above and below aged 65 years for each payer plan, and multiplied by the OAB prevalence data from Stewart et al. (200320; Figure 1). Gender distribution of $\mathrm{OAB}$ patients aged 24-64 years was calculated as $15.7 \%$ male to $16.1 \%$ female and of those aged 65 years and older was $31.6 \%$ male to $31.1 \%$ female.

Despite its prevalence, the real-world OAB population seeking care by talking to their doctors was estimated to be $60 \%$ of the total OAB population. ${ }^{12,24}$ Nonpharmacologically treated patients represented approximately $32 \%$ of the population seeking care and managed their $\mathrm{OAB}$ symptoms with behavioral therapies only (e.g., bladder training, bladder control strategies, pelvic floor muscle training, and fluid management). 3,25 In this BIM, the remaining $68 \%$ of the population seeking care is considered to consist of the following populations:

- Population A: Patients currently treated with an oral pharmacotherapy either with antimuscarinics or mirabegron, making up $9.6 \%$ of the $\mathrm{OAB}$ population seeking care. ${ }^{26}$ 
FIGURE 1 OAB Prevalence and OAB Population Treatment Status per 1 Million-Member Plan from U.S. Commercial Payer and Medicare Advantage Perspectives
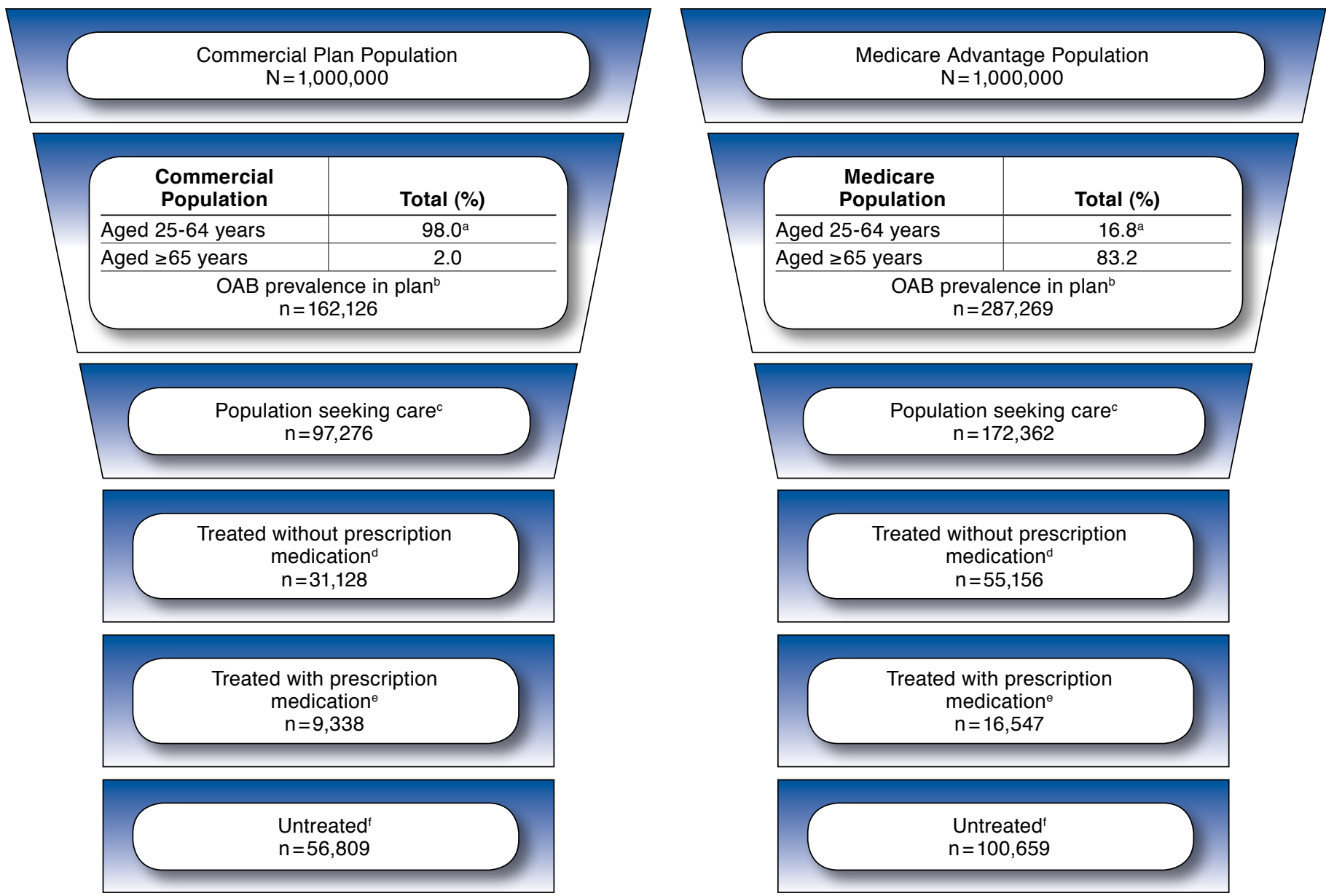

apercentage of commercial plan population aged under 65 years was assumed to be 98.0\%. Medicare Advantage population aged 25-64 years was 16.8\% (disabled). ${ }^{b} O A B$ prevalence in the plan was calculated starting with U.S. Census Bureau population age and gender distribution, bifurcating to strata above and below age 65 years for each payer plan from information shown in footnote a and multiplying by the OAB prevalence. Prevalence was estimated to be $15.7 \%$ male to $16.1 \%$ female among those aged 24-64 years and 31.6\% male to $31.1 \%$ female among those aged $\geq 65$ years.

cPercentage of people with $O A B$ that seek medical care. ${ }^{24}$

dPercentage of people treated with only behavioral therapy is $32.0 \% .25$

ePopulation A is from Ivanova et al. (2014). 26

fUntreated population (population B) includes treatment naive, discontinued, or contraindicated.

$O A B=$ overactive bladder.

- Population B: Patients currently not on an oral pharmacotherapy but eligible to initiate therapy with mirabegron. The untreated portion was estimated to be the remaining 58.4\% of the OAB population seeking care. This portion included patients who had been on an antimuscarinic therapy for $\mathrm{OAB}$ and discontinued for reasons such as a lack of efficacy with antimuscarinics or AEs associated with anticholinergics, as well as patients not eligible for OAB antimuscarinic treatment according to the Beers List or because of high
ACB. ${ }^{4,5,27}$ This BIM allows a user to modify the proportion of these patients to begin therapy with mirabegron.

The focus of this BIM was the oral OAB pharmacotherapies; therefore, patients treated with only behavioral therapy, as well as patients treated with procedures such as sacral neuromodulation, tibial nerve stimulation, and onabotulinumtoxinA, were not considered. All assumptions of this BIM are listed in Appendix A (available in online article). 


\begin{tabular}{|c|c|c|c|c|}
\hline \multicolumn{5}{|c|}{$\begin{array}{l}\text { TABLE 1 Current and Projected Market Shares for } \\
\text { Primary and Secondary Analyses }\end{array}$} \\
\hline Drug Name & $\begin{array}{c}\text { Current } \\
\text { Annual (\%) }\end{array}$ & $\begin{array}{c}\text { Year } 1 \\
(\%)\end{array}$ & $\begin{array}{c}\text { Year } 2 \\
(\%)\end{array}$ & $\begin{array}{c}\text { Year } 3 \\
(\%)\end{array}$ \\
\hline \multicolumn{5}{|l|}{ Primary Analysis } \\
\hline \multicolumn{5}{|c|}{ Population A } \\
\hline Mirabegron & 4.50 & 5.30 & 7.10 & 9.40 \\
\hline Generic antimuscarinics & 66.20 & 65.65 & 64.40 & 62.80 \\
\hline Branded antimuscarinics & 29.30 & 29.05 & 28.50 & 27.80 \\
\hline Total & 100.00 & 100.00 & 100.00 & 100.00 \\
\hline \multicolumn{5}{|c|}{ Population B } \\
\hline Mirabegron & 0.00 & 0.00 & 0.00 & 0.00 \\
\hline Remain untreated & 100.00 & 100.00 & 100.00 & 100.00 \\
\hline Total & 100.00 & 100.00 & 100.00 & 100.00 \\
\hline \multicolumn{5}{|l|}{ Secondary Analysis } \\
\hline \multicolumn{5}{|c|}{ Population A } \\
\hline Mirabegron & 4.50 & 4.50 & 4.50 & 4.50 \\
\hline Generic antimuscarinics & 66.20 & 66.20 & 66.20 & 66.20 \\
\hline Branded antimuscarinics & 29.30 & 29.30 & 29.30 & 29.30 \\
\hline Total & 100.00 & 100.00 & 100.00 & 100.00 \\
\hline \multicolumn{5}{|c|}{ Population B } \\
\hline Mirabegron & 0.00 & 1.00 & 2.00 & 3.00 \\
\hline Remain untreated & 100.00 & 99.00 & 98.00 & 97.00 \\
\hline Total & 100.00 & 100.00 & 100.00 & 100.00 \\
\hline
\end{tabular}

In this BIM, $68 \%$ of the $\mathrm{OAB}$ population seeking care was distributed between populations $\mathrm{A}$ and $\mathrm{B}$, as previously defined. A commercial plan mostly covers patients who are aged younger than 65 years, constituting about $98 \%$ of its members. The Medicare Advantage population covers patients, who are aged 65 years and older $(83.2 \%)$ and who are younger than 65 years and disabled $(16.8 \%) .{ }^{28}$ For a million-member plan from a commercial payer perspective, populations A and B consisted of 9,338 and 56,809 patients, respectively. From a million-member Medicare Advantage plan perspective, because of higher prevalence in the elderly, populations A and B consisted of 16,547 and 100,659 patients, respectively (Figure 1).

\section{Treatments}

For costing, comparator drugs were grouped as either generic or branded antimuscarinics. The generic antimuscarinics consisted of oxybutynin (weighted average of extended-release [ER] and immediate-release [IR] formulations), tolterodine IR and ER, and trospium; the branded antimuscarinics consisted of solifenacin, fesoterodine, and darifenacin (Table 1). Prescription cost per month for each drug was calculated by taking the weighted average of the cost of each available dosage and their market shares (Astellas unpublished data, Marketing Sciences, OAB market pill strength analysis, January 2014). The drug wholesale acquisition cost prices were obtained from RED BOOK Online. ${ }^{29}$

\section{Market Shares}

The current market shares for all comparators in the current $\mathrm{OAB}$ treatment mix were obtained from IMS Health data (unpublished data, IMS Health, Prescription Audit Week, January 24, 2014). The market shares during the 3-year time horizon of the BIM were based on assumptions; the values used in the primary and secondary analyses are given in Table 1. The primary analysis only considered the increased use of mirabegron in population A as patients switched treatment from antimuscarinics to mirabegron, and no movement from population B was considered. The secondary analysis estimated the effect of moving $1 \%$ more of the untreated population each year to the treated population mix by initiating treatment with mirabegron.

Anticholinergic AEs largely account for the high discontinuation rates for antimuscarinics with another cause being lack of efficacy (Appendix A). ${ }^{30-32}$ About $90 \%$ of patients experiencing an AE such as dry mouth or constipation discontinue. ${ }^{30}$ The market share of each treatment and the number of patients on each treatment were assumed constant throughout the year (Appendix A). Because of discontinuations, these assumptions could only be observed by having patients switch between comparators throughout the year.

\section{Costs}

The costs included in this BIM were prescription drug costs and physician visit costs for $\mathrm{OAB}$ and $\mathrm{OAB}$-related comorbidities and ACB-related outpatient and emergency department (ED) visit costs. Prescription and physician visit costs were reported separately for OAB-related comorbidities. A commercial to Medicare reimbursement ratio of 1.53 was used to convert costs between different payer perspectives. ${ }^{33}$ This ratio of 1.53 was imputed using the 6-year average (2008-2013) of the ratio between commercial payer payment-to-cost and Medicare payment-to-cost ratios available from Avalere Health. ${ }^{33} \mathrm{OAB}$ drug prices were assumed to be the same for all payers. Except for the ACB-related costs, pharmacological AE costs were not considered significant for a U.S. payer and not included in this BIM (Appendix A). ${ }^{30}$

Cost of Anticholinergic Cognitive Burden. The Regenstrief Institute's 2012 update of the Aging Brain Care report categorized all direct $O A B$ antimuscarinic drugs with an $A C B$ score of $3 .{ }^{34}$ Mirabegron was approved after this update, so it is not listed in this document. However, no evidence of ACB has been associated with mirabegron, so the model assumed a zero score. In addition, studies have shown that an increased risk of cognitive impairment is associated with long-term use of anticholinergics. ${ }^{35,36}$

For this BIM, Regenstrief Institute conducted an analysis among older adults with and without $\mathrm{OAB}$ and evaluated the link between anticholinergic medications and health care 
utilization. Analysis of the elderly population was relevant, since $\mathrm{OAB}$ and cognitive impairment are more prevalent in this population. ${ }^{18}$ This project used the Regenstrief Medical Record System (RMRS), which contains registration records (demographics); laboratory data; ED, inpatient, and outpatient encounter data; and pharmacy dispensing data. Patients were selected from the Indianapolis Dementia Screening and Diagnosis Study (IDSD), ${ }^{37}$ which included 4,197 participants aged 65 years and older who received primary care within the Eskenazi Health Services, formerly known as Wishard Health Services, in Indianapolis from 2001 to $2004 .^{38}$ For this analysis, the IDSD population data were merged with the RMRS for evaluation of the link between anticholinergic exposure and health care utilization. Data available for this analysis included 10 years of clinical activity and dispensing data that included hospital, outpatient visits, and diagnoses before the screening and diagnosis phase of cognitive assessment. Of the 4,197 participants, 507 were excluded, since they did not have any drugdispensing records during the study period. Screening was between 2001 and 2004. The study included the period dated 10 years before the screening during which the only medication indicated for $\mathrm{OAB}$ was oxybutynin. Although oxybutynin may have higher rates of AEs than the other antimuscarinics, they all have the same ACB score according to the ACB scale ${ }^{34}$; therefore, their impact on the cognitive outcomes and the associated health care utilization were assumed to be the same in this BIM. This analysis demonstrated that higher ACB score was associated with higher health care resource utilization, as well as higher odds of cognitive impairment (including mild cognitive impairment and dementia).

The BIM considered the distribution of patients into $6 \mathrm{ACB}$ levels. Since the study included only patients aged 65 years and older, the BIM assumed a baseline ACB score of 0 for patients aged 25-64 years (Appendix B, available in online article). For patients who were aged 65 years and older, the Regenstrief study population distribution was used: $40 \%$ had an ACB score of 0 and $33.4 \%, 14.8 \%, 7.0 \%, 2.9 \%, 1.2 \%$, and $0.7 \%$ had ACB scores of 1-6+, respectively.

The Regenstrief analysis also provided linear regression equations that estimated the increase in the number of outpatient and ED visits per unit increase in the ACB score. Few patients in the dataset had inpatient visits. The model did not include inpatient visits, since no differences were seen after adjusting for covariates. The estimated changes in resource utilization per ACB score increase are given in Appendix B. The analysis estimated the increases in the number of annual visits per ACB score as 1.135 and 0.114 for outpatient and ED visits, respectively (Appendix B).

Cost of OAB Comorbidities. Comorbidities that are frequently associated with $\mathrm{OAB}$ are depression, skin rashes/infections, and UTIs. ${ }^{10,32,39}$ The annual rates of comorbidities among untreated
$\mathrm{OAB}$ patients are higher than treated OAB patients. ${ }^{10}$ Ko et al. (2006) provided the annual rate of depression for OAB patients who received $\mathrm{OAB}$ treatment as $17 \% .{ }^{10} \mathrm{OAB}$ patients who were not receiving treatment (e.g., treatment naive patients and discontinuers) had higher probability of depression reported as $60 \% .^{10}$ The annual risks for skin rashes and UTIs for patients who were receiving treatment for $\mathrm{OAB}$ were 0.325 and 0.039 , respectively. The risks were higher for untreated $O A B$ patients: 0.825 and 0.114 for skin rashes and UTIs, respectively. ${ }^{10}$

The costs of comorbidities were adjusted to 2015 U.S. dollars by the medical care component of the Consumer Price Index (November 2015). For comorbidities, a 15-minute physician visit was also assumed and the AMA Code Manager CPT value search was used with Current Procedural Terminology code 99213 for cost (American Medical Association, AMA CodeManager, CPT Code/Relative Value Search, national, nonfacility payment of $\$ 73.45$ for Medicare). The prescription drug and physician visit costs for $\mathrm{OAB}$ comorbidity treatments are given in Table $2 .^{10}$

\section{Results}

All of the comparators were assumed to be equally efficacious in this BIM (Appendix A). Annual rates of OAB-related comorbidities were obtained from Ko et al. ${ }^{10}$ The rates were the same for all patients who received $\mathrm{OAB}$ treatment; therefore, comorbidity prescription and physician visit cost estimates were assumed constant across all comparators in this BIM. The rates were higher for untreated OAB patients..$^{10}$ In Table 2, comorbidity costs were highest in untreated patients (population B). From the Medicare Advantage perspective, using 1 to 1.53 as the Medicare to commercial reimbursement ratio, the comorbidity prescription and physician visit costs for a treated patient were $\$ 45.18$ and $\$ 39.22$, respectively (Table 2 ). The costs for an untreated patient in the Medicare Advantage plan were $\$ 150.19$ and $\$ 113.04$ and in a commercial plan were $\$ 229.78$ and $\$ 172.95$, respectively.

Table 2 displays physician visit costs per patient year for each comparator. The average number of physician visits during a year was different for each comparator because persistence rates for each drug are different (Appendix A), and each treatment initiation, including switching between comparators, incurred 1 physician visit. Drugs with lower persistence had more patients switching to other drugs, which resulted in more physician visits, thus, incurring a higher total physician visit cost per year than drugs with higher persistence. Mirabegron had the lowest annual cost for physician visits: $\$ 248.59$ from a U.S. commercial plan and $\$ 162.48$ from a Medicare Advantage plan.

For Medicare Advantage, each of the antimuscarinics cost $\$ 594.50$ annually for ACB-related outpatient visits and \$216.77 for ACB-related ED visits. The costs incurred by a commercial plan were $\$ 551.40$ and $\$ 166.42$ for outpatient and ED visits, respectively. Since it is believed that mirabegron does 
TABLE 2 Cost per Year Treatment for Commercial and Medicare Advantage (Not Adjusted for Market Shares)

\begin{tabular}{|c|c|c|c|c|c|c|}
\hline Comparators & $\begin{array}{l}\text { OAB Prescription } \\
\text { Costs (\$) }\end{array}$ & $\begin{array}{l}\text { Physician Visit } \\
\text { Costs (\$) }\end{array}$ & $\begin{array}{l}\text { ACB Outpatient } \\
\text { Visit Costs }(\$)^{\mathrm{a}}\end{array}$ & $\begin{array}{l}\text { ACB ED Visit } \\
\text { Costs }(\$)^{\mathrm{b}}\end{array}$ & $\begin{array}{c}\text { Comorbidity } \\
\text { Prescription } \\
\text { Costs }(\$)^{\mathrm{c}}\end{array}$ & $\begin{array}{l}\text { Comorbidity } \\
\text { Medical } \\
\text { Costs }(\$)^{\mathrm{d}}\end{array}$ \\
\hline \multicolumn{7}{|l|}{ Commercial } \\
\hline Mirabegron & $3,314.16$ & 248.59 & 5.58 & 1.17 & 69.13 & 60.01 \\
\hline Fesoterodine & $2,795.28$ & 456.77 & \multirow{7}{*}{551.40} & \multirow{7}{*}{166.42} & \multirow{7}{*}{69.13} & \multirow{7}{*}{60.01} \\
\hline Darifenacin & $3,405.48$ & 404.77 & & & & \\
\hline Solifenacin & $3,226.44$ & 354.30 & & & & \\
\hline Tolterodine IR & $1,170.84$ & 397.25 & & & & \\
\hline Tolterodine ER & $2,349.48$ & 427.33 & & & & \\
\hline Oxybutynin & 637.56 & 430.74 & & & & \\
\hline Trospium & 829.44 & 536.10 & & & & \\
\hline Untreated population & - & - & 5.58 & 1.17 & 229.78 & 172.95 \\
\hline \multicolumn{7}{|l|}{ Medicare Advantage } \\
\hline Mirabegron & $3,314.16$ & 162.48 & 138.90 & 48.98 & 45.18 & 39.22 \\
\hline Fesoterodine & $2,795.28$ & 298.54 & \multirow{7}{*}{594.50} & \multirow{7}{*}{216.77} & \multirow{7}{*}{45.18} & \multirow{7}{*}{39.22} \\
\hline Darifenacin & $3,405.48$ & 264.55 & & & & \\
\hline Solifenacin & $3,226.44$ & 231.57 & & & & \\
\hline Tolterodine IR & $1,170.84$ & 259.64 & & & & \\
\hline Tolterodine ER & $2,349.48$ & 279.30 & & & & \\
\hline Oxybutynin & 637.56 & 281.53 & & & & \\
\hline Trospium & 829.44 & 350.39 & & & & \\
\hline Untreated population & - & - & 138.90 & 48.98 & 150.19 & 113.04 \\
\hline
\end{tabular}

a ACB-related outpatient costs were calculated based on $\$ 214.83$ per visit. The outpatient visit cost was a weighted average of PCP and specialist visit costs using a 0.6 to 0.4 for specialist to $P C P$ visit ratio.

${ }^{b}$ ACB-related ED visit costs were calculated based on $\$ 800.05$ per visit.

'Prescription costs included depression, skin rashes, and UTI costs. ${ }^{10}$ For Medicare Advantage, the prescription costs per comorbidity episode were $\$ 205.31$, $\$ 24.35$, and $\$ 60.58$ for depression, skin rashes, and UTI, respectively.

${ }^{\mathrm{M}}$ Medical costs included physician visit costs for depression, skin rashes, and UTIs and were equal to $\$ 73.45$ per comorbidity episode for Medicare Advantage (American Medical Association, AMA CodeManager, CPT Code/Relative Value Search, national, nonfacility payment of \$73.45 for Medicare).

$A C B=$ anticholinergic cognitive burden; $E D=$ emergency department; $E R=$ extended release; $I R=$ immediate release; $O A B=$ overactive bladder; $P C P=$ primary care physician; UTI = urinary tract infection.

not affect the cholinergic pathways, it did not incur any $O A B$ treatment-related ACB costs but incurred the non-OAB ACB. From the Medicare Advantage perspective, patients on mirabegron incurred outpatient and ED visit costs of $\$ 138.90$ and $\$ 48.98$, respectively; the same costs from a commercial payer perspective were $\$ 5.58$ and $\$ 1.17$, respectively. The ACB costs for untreated $O A B$ patients were equal to mirabegron patients, since they only incurred the non-OAB ACB.

\section{Primary Analysis}

The economic outcomes for the primary analysis (Table 3) were obtained by adjusting the per patient year costs in Table 2 by multiplying them by the population distribution for the payer plan and with the market shares. While increased use of mirabegron increased the prescription costs, the total medical costs decreased because of the lower number of visits as a result of ACB. The per member per month (PMPM) costs incurred were $\$ 0.010, \$ 0.034$, and $\$ 0.065$ by the Medicare Advantage plan and $\$ 0.005, \$ 0.016$, and $\$ 0.031$ by the commercial payer. Per treated member per month (PTMPM) costs increased by an average of less than $2 \%$ of the current $\mathrm{OAB}$ treatment costs for commercial payers and for Medicare Advantage (Table 3).

The clinical outcomes were presented in terms of the number of AEs that could be avoided by an increase in the use of mirabegron in a million-member plan. In the primary analysis, since no patients from population B initiated oral pharmacotherapy and the number of comorbidity episodes did not vary among treatments, no comorbidity events were avoided, so there were no cost savings from avoided $\mathrm{OAB}$ comorbidities. The numbers of AEs for dry mouth, constipation, and blurry vision were calculated based on the AE rates of each treatment taken from the prescribing information. Mirabegron has the lowest rates of dry mouth, constipation, and blurry vision. Increased use of mirabegron in a commercial payer plan, as patients switched from antimuscarinics, reduced the total number of dry mouth events by 253 (i.e., 24 events in year 1; 79 and 150 events in years 2 and 3, respectively); constipation events by 51 ( 5,16 , and 30 in 3 years, respectively); and blurry vision events by 30 (3, 9, and 18 in 3 years, respectively). The total reductions in 3 years for the Medicare Advantage plan 


\section{TABLE 3 Economic and Clinical Outcomes of Primary Analysis}

\begin{tabular}{|c|c|c|c|c|c|c|c|}
\hline & $\begin{array}{c}\text { OAB } \\
\text { Prescription } \\
\text { Costs }(\$)\end{array}$ & $\begin{array}{c}\text { Comorbidity } \\
\text { Prescription } \\
\text { Costs }(\$)\end{array}$ & $\begin{array}{c}\text { Total } \\
\text { Prescription } \\
\text { Costs }(\$)\end{array}$ & $\begin{array}{l}\text { Total Medical } \\
\text { Costs }(\$)\end{array}$ & Total Cost $(\$)$ & PTMPM (\$) & PMPM (\$) \\
\hline Current values & $15,926,271$ & $13,699,343$ & $29,625,614$ & $20,990,719$ & $50,616,332$ & 200.20 & 4.218 \\
\hline \multicolumn{8}{|l|}{ Incrementala } \\
\hline Year 1 & 125,291 & - & 125,291 & $(65,672)^{\mathrm{b}}$ & 59,619 & 0.90 & 0.005 \\
\hline Year 2 & 408,471 & - & 408,471 & $(213,352)^{\mathrm{b}}$ & 195,119 & 2.92 & 0.016 \\
\hline \multirow[t]{2}{*}{ Year 3} & 772,399 & - & 772,399 & $(402,148)^{\mathrm{b}}$ & 370,250 & 5.53 & 0.031 \\
\hline & $\begin{array}{c}\text { Total AEs } \\
\text { Net Avoided } \\
\end{array}$ & & & & & & \\
\hline Year 1 & 32 & & & & & & \\
\hline Year 2 & 105 & & & & & & \\
\hline Year 3 & 198 & & & & & & \\
\hline \multicolumn{8}{|c|}{ Medicare Advantage: Economic and Clinical Outcomes } \\
\hline & $\begin{array}{c}\text { OAB } \\
\text { Prescription } \\
\text { Costs }(\$)\end{array}$ & $\begin{array}{c}\text { Comorbidity } \\
\text { Prescription } \\
\text { Costs }(\$)\end{array}$ & $\begin{array}{c}\text { Total } \\
\text { Prescription } \\
\text { Costs }(\$)\end{array}$ & $\begin{array}{l}\text { Total Medical } \\
\text { Costs }(\$)\end{array}$ & Total Cost $(\$)$ & PTMPM (\$) & PMPM (\$) \\
\hline Current values & $28,219,566$ & $15,865,162$ & $44,084,729$ & $48,319,758$ & $92,404,486$ & 188.85 & 7.700 \\
\hline \multicolumn{8}{|l|}{ Incrementala } \\
\hline Year 1 & 222,002 & - & 222,002 & $(97,054)^{\mathrm{b}}$ & 124,948 & 0.93 & 0.010 \\
\hline Year 2 & 723,765 & - & 723,765 & $(315,331)^{\mathrm{b}}$ & 408,434 & 3.04 & 0.034 \\
\hline \multirow[t]{2}{*}{ Year 3} & $1,368,604$ & - & $1,368,604$ & $(594,348)^{\mathrm{b}}$ & 774,256 & 5.76 & 0.065 \\
\hline & $\begin{array}{c}\text { Total AEs } \\
\text { Net Avoided } \\
\end{array}$ & & & & & & \\
\hline Year 1 & 57 & & & & & & \\
\hline Year 2 & 185 & & & & & & \\
\hline Year 3 & 351 & & & & & & \\
\hline
\end{tabular}

were 448, 92, and 54 for dry mouth, constipation, and blurry vision, respectively. The total number of avoided AEs during each year is the sum of numbers of all avoided events for that year (e.g., $24+5+3=32$ events avoided in year 1; approximately 105 and 198 events were avoided in years 2 and 3, respectively, for a commercial payer plan; Table 3). The estimated yearly total numbers of avoided AEs for the Medicare Advantage plan were 57, 185, and 351 (Table 3).

Primary analysis included a one-way sensitivity analysis on 8 variables (Figure 2A-B). The model was most sensitive to mirabegron market shares and cost per month and the percentage of the population treated with prescription $\mathrm{OAB}$ medication from commercial payer and Medicare Advantage perspectives.

\section{Secondary Analysis}

Increased use of mirabegron resulted in higher prescription costs and slightly higher medical costs (Table 4). The economic outcomes for the secondary analysis were obtained by multiplying the per-patient costs shown in Table 2 by the corresponding market shares and the age/gender distributions for each payer plan. In the secondary analysis, the number of comorbidities decreased as a portion of the untreated population B initiated therapy with mirabegron (Table 4). Reduction in the number of untreated $\mathrm{OAB}$ comorbidity episodes reduced the costs incurred by the payers for the comorbidities. The PMPM costs incurred increased from current value by $\$ 0.277$, $\$ 0.553$, and $\$ 0.830$ for Medicare Advantage and increased by $\$ 0.156, \$ 0.311$, and $\$ 0.467$ for a commercial payer. Secondary analysis estimated increases in PTMPM costs of an average of less than $6.5 \%$ and $6 \%$ for Medicare Advantage and commercial payers, respectively. Total savings in prescription costs from avoided comorbidities for both plans are given in Table 4.

One-way sensitivity analysis tornado diagrams for the secondary analysis are shown in Figure 2C-D. The model was most sensitive to mirabegron market shares, percentage of $\mathrm{OAB}$ population seeking care, $\mathrm{OAB}$ prevalence, mirabegron costs per month, and percentage of untreated population starting treatment with mirabegron in year 3 .

\section{Discussion}

A BIM was developed to analyze the economic and clinical consequences of increased use of mirabegron for the treatment 


\section{Base Case $=\$ 0.017$}

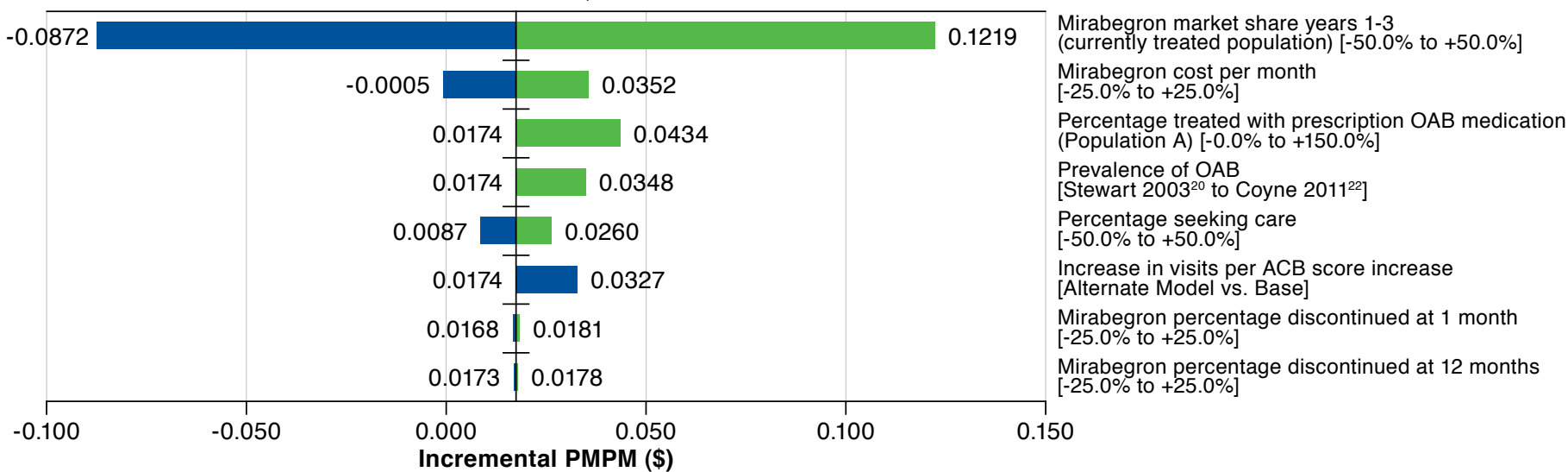

B. Primary Analysis: 3-Year Incremental PMPM (Medicare Advantage)

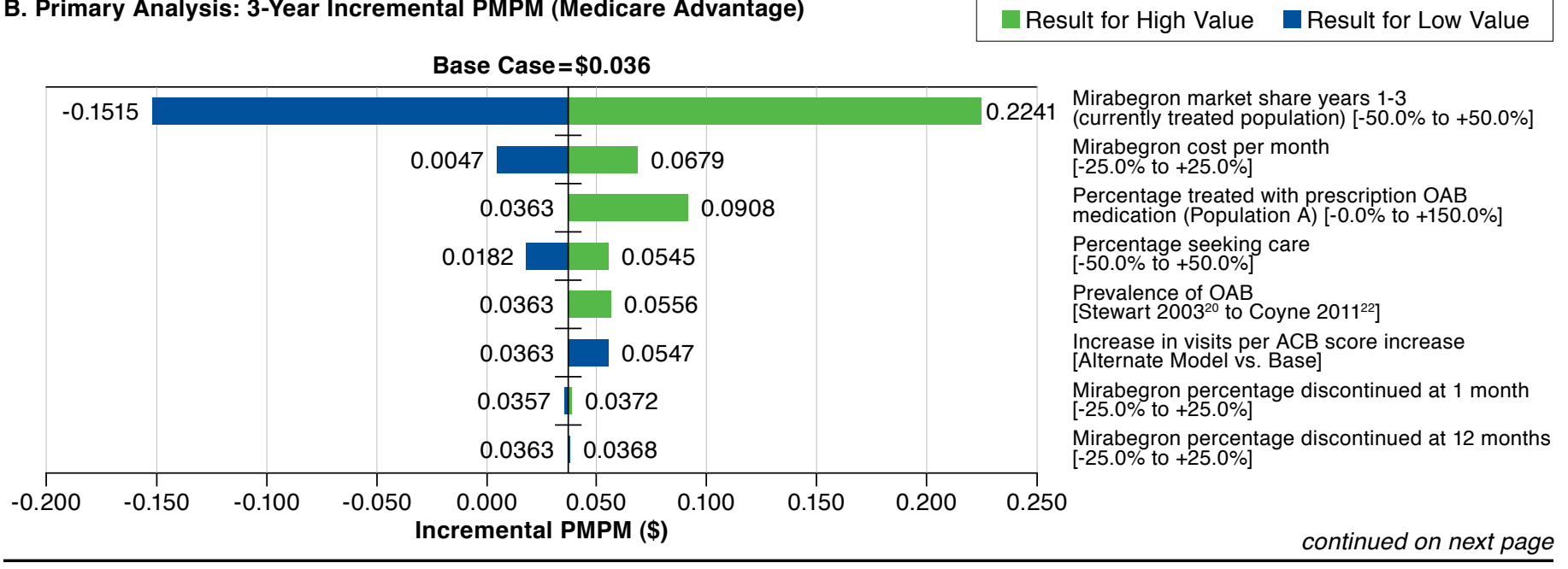

of OAB symptoms from the perspectives of a U.S. commercial payer and Medicare Advantage. This is the first BIM that has analyzed the budgetary impact of increased use of mirabegron from generic and branded antimuscarinics, which also includes the ACB scale and ACB-related increase in the health care utilization costs in the United States. ${ }^{27}$ In addition, this BIM considered the differences in $\mathrm{OAB}$ treatment persistence and the impact on treatment cost (Appendix A). ${ }^{31}$

This BIM has the capability to model patients moving onto treatment with pharmacotherapy from the currently untreated population, allowing users to evaluate the budgetary impact of growing the size of the treated patient population. The effect on the medical budget of a decrease in the untreated population is through OAB-related comorbidities avoided. As more patients are treated, fewer comorbidity events occur, so reduced comorbidity-related prescription and HRU costs offset part of the added cost of pharmacological treatment with mirabegron. The cost offsets in the newly treated population are higher per person for a commercial plan than for Medicare Advantage because commercial medical cost inputs are higher. Overall costs are higher for Medicare Advantage because the older, more ill population has higher OAB prevalence.

Antimuscarinics contribute to ACB, which is associated with increased HRU. Based on a retrospective database analysis of a large health care system, the increase in the number of outpatient and ED visits were estimated per unit increase in ACB scores. All of the antimuscarinics have been attributed a score of 3 according to the ACB scale, whereas mirabegron was not included in the list of medications that affected ACB. Because of mirabegron's lack of affinity for muscarinic/cholinergic 


\section{FIGURE 2 Tornado Diagrams for One-Way Sensitivity Analyses (continued)}

C. Secondary Analysis: 3-Year Incremental PMPM (Commercial)

Base Case $=\$ 0.311$

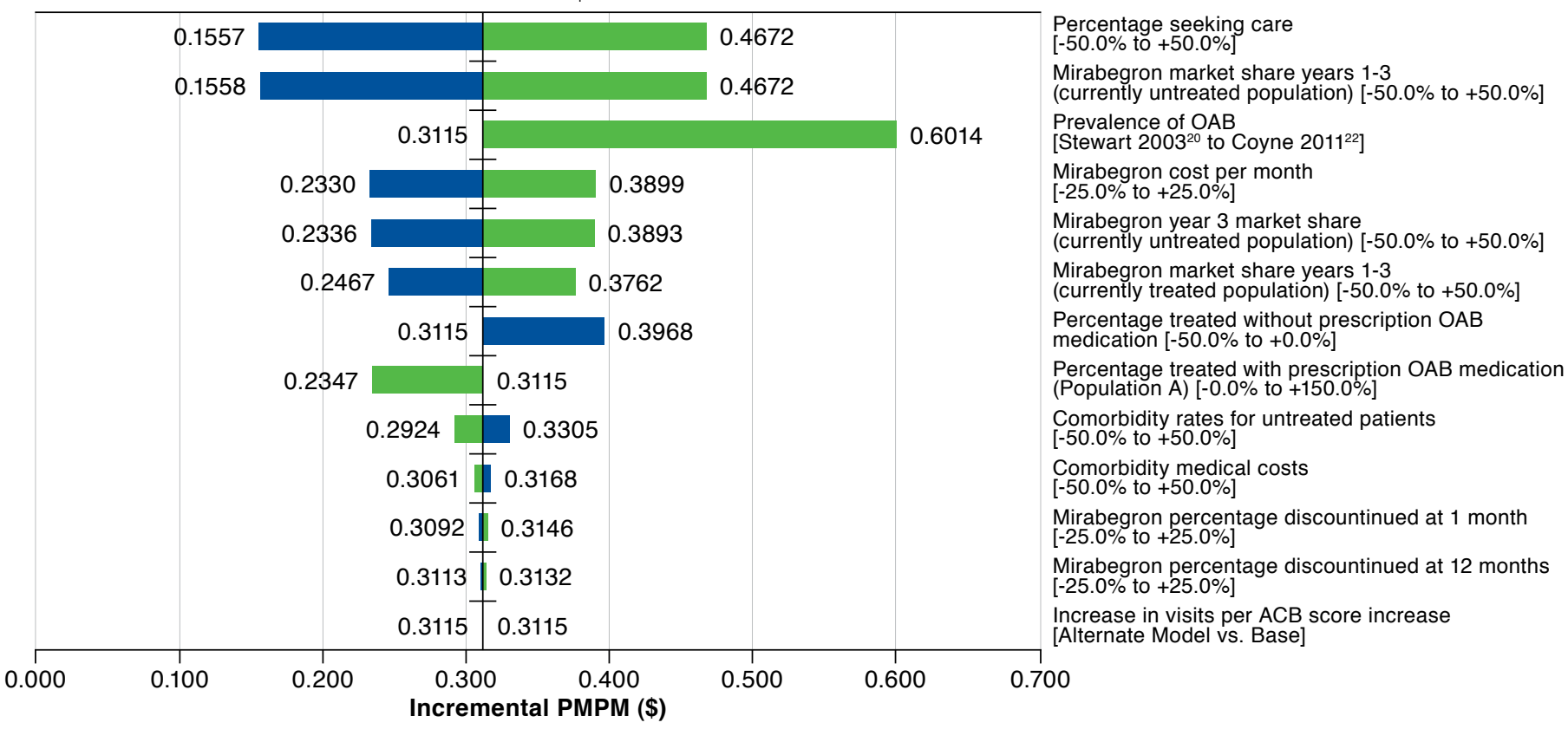

D. Secondary Analysis: 3-Year Incremental PMPM (Medicare Advantage)

Result for High Value $\quad$ Result for Low Value

Base Case $=\$ 0.553$

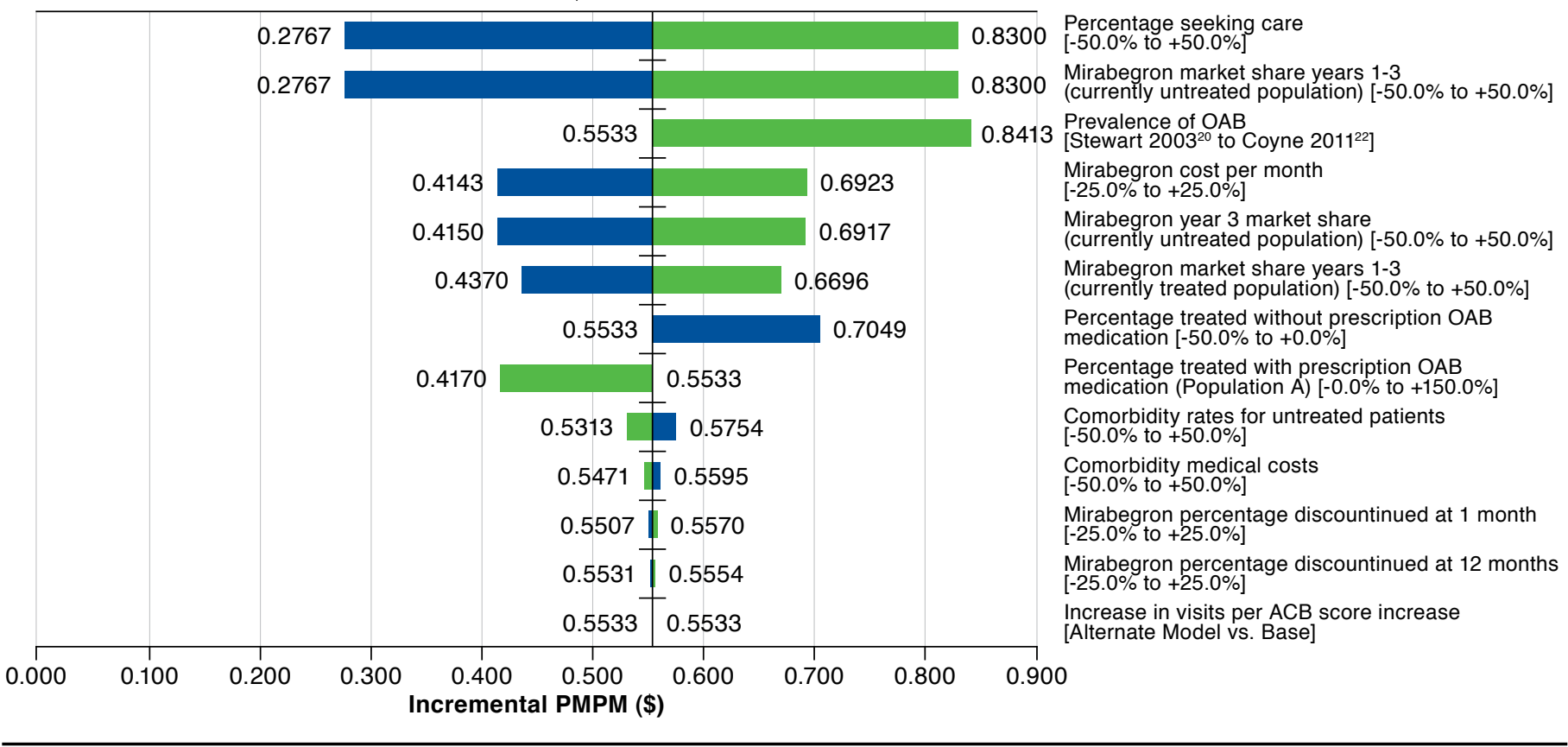

$A C B=$ anticholinergic cognitive burden; $O A B=$ overactive bladder; $P M P M=$ per member per month
Result for High Value $\quad$ Result for Low Value

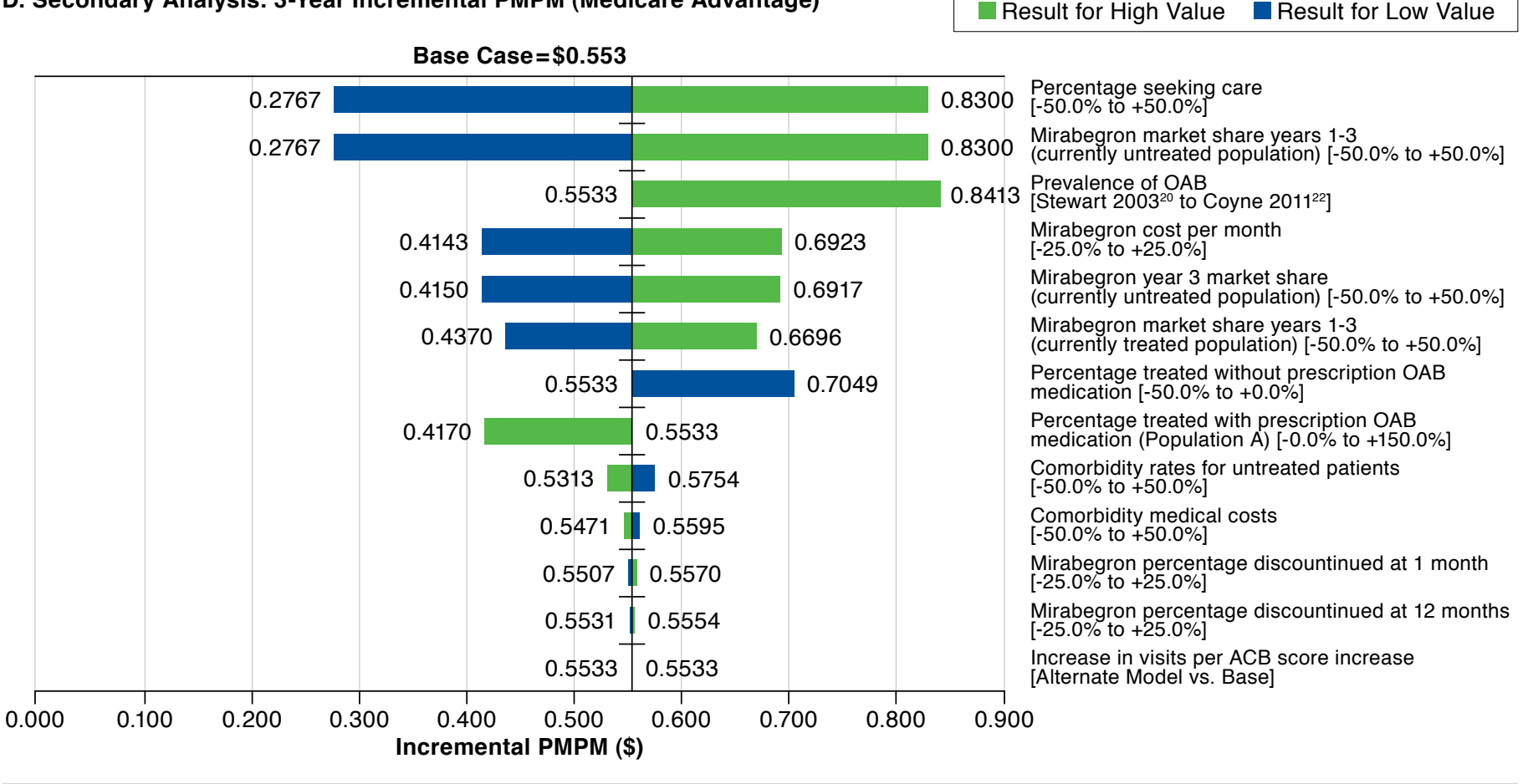


TABLE 4 Economic and Clinical Outcomes of Secondary Analysis

\begin{tabular}{|c|c|c|c|c|c|c|c|c|}
\hline & $\begin{array}{c}\text { Number of } \\
\text { Patients Treated }\end{array}$ & $\begin{array}{c}\text { OAB } \\
\text { Prescription } \\
\text { Costs }(\$)\end{array}$ & $\begin{array}{c}\text { Comorbidity } \\
\text { Prescription } \\
\text { Costs }(\$)\end{array}$ & $\begin{array}{c}\text { Total } \\
\text { Prescription } \\
\text { Costs }(\$)\end{array}$ & $\begin{array}{l}\text { Total Medical } \\
\text { Costs }(\$)\end{array}$ & Total Cost (\$) & PTMPM (\$) & PMPM (\$) \\
\hline Current values & 9,338 & $15,926,271$ & $13,699,343$ & $29,625,614$ & $20,990,719$ & $50,616,332$ & 200.20 & 4.218 \\
\hline \multicolumn{9}{|l|}{ Incremental $^{\mathrm{a}}$} \\
\hline Year 1 & 568 & $1,882,741$ & $(91,268)^{b}$ & $1,791,473$ & 77,059 & $1,868,532$ & 6.17 & 0.156 \\
\hline Year 2 & 1,136 & $3,765,482$ & $(182,536)^{\mathrm{b}}$ & $3,582,946$ & 154,118 & $3,737,064$ & 11.67 & 0.311 \\
\hline \multirow[t]{4}{*}{ Year 3} & 1,704 & $5,649,822$ & $(273,804)^{b}$ & $5,376,018$ & 231,173 & $5,607,191$ & 16.61 & 0.467 \\
\hline & \multicolumn{7}{|c|}{ Comorbidities Avoided and Associated Net Savings } & \\
\hline & \multirow{2}{*}{$\begin{array}{c}\text { Total AEs Net } \\
\text { Increase }^{c}\end{array}$} & \multicolumn{2}{|c|}{ UTI } & \multicolumn{2}{|c|}{ Depression } & \multicolumn{2}{|c|}{ Skin Rashes } & \\
\hline & & Number & Net Savings (\$) & Number & Net Savings (\$) & Number & Net Savings (\$) & \\
\hline Year 1 & 1 & 43 & 8,737 & 244 & 104,187 & 284 & 42,504 & \\
\hline Year 2 & 2 & 85 & 17,475 & 489 & 208,375 & 568 & 85,009 & \\
\hline Year 3 & 3 & 128 & 26,212 & 733 & 312,562 & 852 & 127,513 & \\
\hline \multicolumn{9}{|c|}{ Medicare Advantage: Economic and Clinical Outcomes } \\
\hline & $\begin{array}{c}\text { Number of } \\
\text { Patients Treated }\end{array}$ & $\begin{array}{c}\text { OAB } \\
\text { Prescription } \\
\text { Costs }(\$)\end{array}$ & $\begin{array}{c}\text { Comorbidity } \\
\text { Prescription } \\
\text { Costs }(\$)\end{array}$ & $\begin{array}{c}\text { Total } \\
\text { Prescription } \\
\text { Costs }(\$) \\
\end{array}$ & $\begin{array}{l}\text { Total Medical } \\
\text { Costs }(\$)\end{array}$ & Total Cost $(\$)$ & PTMPM (\$) & PMPM (\$) \\
\hline Current values & 16,547 & $28,219,566$ & $15,865,162$ & $44,084,729$ & $48,319,758$ & $92,404,486$ & 188.85 & 7.700 \\
\hline \multicolumn{9}{|l|}{ Incremental $^{\mathrm{a}}$} \\
\hline Year 1 & 1,007 & $3,336,006$ & $(105,697)^{\mathrm{b}}$ & $3,230,309$ & 89,242 & $3,319,550$ & 6.42 & 0.277 \\
\hline Year 2 & 2,013 & $6,672,012$ & $(211,394)^{b}$ & $6,460,617$ & 178,483 & $6,639,100$ & 12.15 & 0.553 \\
\hline \multirow[t]{4}{*}{ Year 3} & 3,020 & $10,010,850$ & $(317,091)^{\mathrm{b}}$ & $9,693,759$ & 267,721 & $9,961,480$ & 17.29 & 0.830 \\
\hline & \multicolumn{7}{|c|}{ Comorbidities Avoided and Associated Net Savings } & \\
\hline & \multirow{2}{*}{$\begin{array}{c}\text { Total AEs Net } \\
\text { Increase }^{c}\end{array}$} & \multicolumn{2}{|c|}{ UTI } & \multicolumn{2}{|c|}{ Depression } & \multicolumn{2}{|c|}{ Skin Rashes } & \\
\hline & & Number & Net Savings (\$) & Number & Net Savings (\$) & Number & Net Savings (\$) & \\
\hline Year 1 & 2 & 75 & 10,119 & 433 & 120,659 & 503 & 49,224 & \\
\hline Year 2 & 4 & 151 & 20,237 & 866 & 241,318 & 1,007 & 98,449 & \\
\hline Year 3 & 5 & 226 & 30,356 & 1,299 & 361,977 & 1,510 & 147,673 & \\
\hline
\end{tabular}

ancremental based on change from current utilization values.

bParenthetical incremental costs denote reduction from current value.

'Total AEs include dry mouth, constipation, and blurry vision.

$A E s=$ adverse events; OAB = overactive bladder; $P M P M=$ per member per month; $P T M P M=$ per treated member per month; UTI = urinary tract infection

receptors and no pattern of muscarinic/cholinergic adverse events, it was assumed that mirabegron does not increase a patient's ACB. Therefore, the ACB costs for outpatient and ED visits were least expensive for mirabegron. Although there have been studies that reported the impact of ACB on cognitive and physical functions and mortality, ${ }^{35,40,41}$ the impact on HRU has not been previously quantified or included in a BIM.

The sensitivity analyses revealed that the BIM was sensitive to the mirabegron market shares, drug cost per month, percentage of $\mathrm{OAB}$ population seeking care, and $\mathrm{OAB}$ prevalence.

The focus of this BIM was OAB oral pharmacotherapy; therefore, the patient populations that are treated with only behavioral therapy or invasive procedures were not considered in this model. Thus, potential savings from postponing or avoiding third-line invasive procedures were not included.

\section{Limitations}

This BIM has some limitations to consider. An assumption of this prevalence-based BIM (see Appendix A) was that the market shares and, hence, the number of patients on each treatment, were constant throughout the year despite the high discontinuation rates among patients taking antimuscarinic treatments. This assumption could only be implemented by having an equal number of patients initiate and discontinue a particular treatment. Therefore, a treatment with lower persistence had more patients discontinuing and also more patients initiating. Another assumption was that the treatment persistence reached at the end of the first year was maintained in the following years. For the first year, after the end of the first month, persistence was assumed to follow an exponential decay curve and maintain the value it reached at the end of the first year until the end of the model time horizon. The risks and associated costs 
of falls and fractures were not included in the model in order to provide a conservative cost estimate, since falls and fractures may depend on factors other than OAB.

AE costs, except for ACB-related costs, are not included in the model and are only reported as clinical outcomes. Furthermore, the model did not include and thus did not quantify the number of events for AEs associated with mirabegron, such as hypertension. In a published study of the pooled analysis of clinical trials of mirabegron, ${ }^{17}$ the incidence of hypertension and headache in the total mirabegron group (25 mg, $50 \mathrm{mg}$, and $100 \mathrm{mg}$ dosages) was found to be similar to placebo and tolterodine ER $4 \mathrm{mg}$, a finding supported by other published studies. ${ }^{42,43}$ Mirabegron is not recommended in severe uncontrolled hypertensive patients with systolic blood pressure $\geq 180 \mathrm{mmHg}$ and/or diastolic blood pressure $\geq 110$ $\mathrm{mmHg}$ because those patients were excluded from the mirabegron clinical trials. ${ }^{42-44}$

The ACB-related costs were calculated using a retrospective analysis of data from a dementia screening study. To the best of our knowledge, this is the first analysis that draws the link between anticholinergic medication use and increased health care utilization. Data available for this analysis included 10 years of clinical activity and dispensing data before the screening, which took place between 2001 and 2004. ${ }^{37,38}$ Although the only medication indicated for $\mathrm{OAB}$ was oxybutynin, and it may have higher rates of AEs than other antimuscarinics, they all have the same ACB score according to the ACB scale. ${ }^{34}$ Therefore, their effects on the cognitive outcomes and the associated health care utilization were assumed to be the same in this BIM.

\section{Conclusions}

Budgetary and clinical outcomes of increased use of mirabegron were examined from the commercial and Medicare Advantage perspectives. Based on the analyses used in this BIM, mirabegron may meet a need in $\mathrm{OAB}$ therapy for patient populations using anticholinergics and also for those currently untreated for OAB with moderate additional economic costs to U.S. payers.

\section{Authors}

SINEM PERK, PhD; RONALD C. WIELAGE, MPH; TIMOTHY M. KLEIN, BS; and ROBERT W. KLEIN, MS, Medical Decision Modeling, Indianapolis, Indiana. NOLL L. CAMPBELL, PharmD, Center for Aging Research, Regenstrief Institute, Indianapolis, Indiana, and Purdue University College of Pharmacy, West Lafayette, Indiana. ANTHONY PERKINS, MS, Center for Aging Research, Regenstrief Institute, Indianapolis, Indiana. LINDA M. POSTA, PharmD, MBA; THOMAS YURAN, PharmD; and DANIEL B. NG, PharmD, MBA, Medical Affairs, Americas, Astellas Pharmaceutical Global Development, Northbrook, Illinois.

AUTHOR CORRESPONDENCE: Sinem Perk, PhD,

Medical Decision Modeling, 201 N. Illinois St., Ste. 1730,

Indianapolis, IN 46204. E-mail: sp@mdm-inc.com.

\section{DISCLOSURES}

Funding for this study was provided by Astellas. Perk, Wielage, T. Klein, and R. Klein are employed by Medical Decision Modeling, a contract research company that was paid to perform the described outcomes research and build the model contained in this study. Campbell and Perkins are employed by the Regenstrief Institute, which conducted a database analysis for this research. Campbell reports consultancy fees from Astellas, as well as pending grants from Merck, Sharpe, and Dohme Corp. Posta, Yuran, and Ng are employed by Astellas Pharma Global Development, the developer of mirabegron.

Study concept and design were contributed by Perk, Wielage, R. Klein, and Ng. Campbell, T. Klein, and Perkins took the lead in data collection, assisted by Perk, Wielage, and Ng. Data interpretation was performed by Posta and Yuran, along with Perk, Wielage, R. Klein, Ng, Campbell, and Perkins. The manuscript was written by Perk and R. Klein, along with Wielage, T. Klein, Posta, Yuran, and Ng, and revised by all the authors.

\section{REFERENCES}

1. Abrams P, Cardozo L, Fall M, et al. The standardisation of terminology in lower urinary tract function: report from the standardisation sub-committee of the International Continence Society. Urology. 2003;61(1):37-49.

2. Haylen BT, de Ridder D, Freeman RM, et al. An International Urogynecological Association (IUGA)/International Continence Society (ICS) joint report on the terminology for female pelvic floor dysfunction. Int Urogynecol J. 2010;21(1):5-26

3. Gormley EA, Lightner DJ, Burgio KL, et al. Diagnosis and treatment of overactive bladder (non-neurogenic) in adults: AUA/SUFU guideline. J Urol. 2012;188(6 Suppl):2455-63. Available at: http://www.jurology.com/article/ S0022-5347(12)04959-2/abstract. Accessed July 19, 2016.

4. American Geriatrics Society 2012 Beers Criteria Update Expert Panel. American Geriatrics Society updated Beers Criteria for potentially inappropriate medication use in older adults. J Am Geriatr Soc. 2012;60(4):616-31.

5. American Geriatrics Society 2015 Beers Criteria Update Expert Panel. American Geriatrics Society 2015 updated Beers Criteria for potentially inappropriate medication use in older adults. J Am Geriatr Soc. 2015;63(11):2227-46.

6. Geller EJ, Crane AK, Wells EC, et al. Effect of anticholinergic use for the treatment of overactive bladder on cognitive function in postmenopausal women. Clin Drug Investig. 2012;32(10):697-705. Available at: http://www. ncbi.nlm.nih.gov/pmc/articles/PMC3572901/. Accessed July 19, 2016

7. Ganz ML, Smalarz AM, Krupski TL, et al. Economic costs of overactive bladder in the United States. Urology. 2010;75(3):526-32, 532.el-e18.

8. Hu TW, Wagner TH, Bentkover JD, et al. Estimated economic costs of overactive bladder in the United States. Urology. 2003;61(6):1123-28.

9. Hu TW, Wagner TH. Health-related consequences of overactive bladder: an economic perspective. BJU Int. 2005;96(Suppl 1):43-45. Available at: http://onlinelibrary.wiley.com/doi/10.1111/j.1464-410X.2005.05654.x/abst ract;jsessionid=44BBB6FF9A12E88507BFB9E2724688EB.f03t02. Accessed July 19, 2016.

10. Ko Y, Malone DC, Armstrong EP. Pharmacoeconomic evaluation of antimuscarinic agents for the treatment of overactive bladder. Pharmacotherapy. 2006;26(12):1694-702.

11. Reeves P, Irwin D, Kelleher C, et al. The current and future burden and cost of overactive bladder in five European countries. Eur Urol. 2006;50(5):1050-57. 
12. Cisternas MG, Foreman AJ, Marshall TS, Runken MC, Kobashi KC, Seifeldin R. Estimating the prevalence and economic burden of overactive bladder among Medicare beneficiaries prior to Medicare Part D coverage. Curr Med Res Opin. 2009;25(4):911-19.

13. Noe L, Sneeringer R, Patel B, Williamson T. The implications of poor medication persistence with treatment for overactive bladder. Manag Care Interface. 2004;17(11):54-60.

14. Chancellor MB, Migliaccio-Walle K, Bramley TJ, Chaudhari SL, Corbell C, Globe D. Long-term patterns of use and treatment failure with anticholinergic agents for overactive bladder. Clin Ther. 2013;35(11):1744-51. Available at: http://www.clinicaltherapeutics.com/article/S0149-2918(13)00943-0/ abstract. Accessed July 19, 2016.

15. Balkrishnan R, Bhosle MJ, Camacho FT, Anderson RT. Predictors of medication adherence and associated health care costs in an older population with overactive bladder syndrome: a longitudinal cohort study. J Urol. 2006;175(3 Pt 1):1067-71.

16. Chapple CR, Amarenco G, López Aramburu MA, et al. A proof-ofconcept study: mirabegron, a new therapy for overactive bladder. Neurourol Urodyn. 2013;32(8):1116-22. Available at: http://onlinelibrary.wiley.com/ doi/10.1002/nau.22373/abstract. Accessed July 19, 2016.

17. Nitti VW, Khullar V, van Kerrebroeck P, et al. Mirabegron for the treatment of overactive bladder: a prespecified pooled efficacy analysis and pooled safety analysis of three randomised, double-blind, placebo-controlled, phase III studies. Int J Clin Pract. 2013;67(7):619-32. Available at: http://www.ncbi. nlm.nih.gov/pmc/articles/PMC3752932/. Accessed July 19, 2016.

18. Pagoria D, O'Connor RC, Guralnick ML. Antimuscarinic drugs: review of the cognitive impact when used to treat overactive bladder in elderly patients. Curr Urol Rep. 2011;12(5):351-57.

19. Jundt K, Schreyer K, Friese K, Peschers U. Anticholinergic therapy: do the patients take the pills prescribed? Arch Gynecol Obstet. 2011;284(3):663-66.

20. Stewart WF, Van Rooyen JB, Cundiff GW, et al. Prevalence and burden of overactive bladder in the United States. World J Urol. 2003;20(6):327-36.

21. Milsom I, Coyne KS, Nicholson S, Kvasz M, Chen CI, Wein AJ. Global prevalence and economic burden of urgency urinary incontinence: a systematic review. Eur Urol. 2014;65(1):79-95.

22. Coyne KS, Sexton CC, Vats V, Thompson C, Kopp ZS, Milsom I. National community prevalence of overactive bladder in the United States stratified by sex and age. Urology. 2011;77(5):1081-87.

23. U.S. Census Bureau. Current population survey, annual social and economic supplement, 2012. Table 1: Population by age and sex: 2012. Available at: https://www.census.gov/population/age/data/ files/2012/2012gender_tablel.xlsx. Accessed August 3, 2016.

24. Milsom I, Abrams P, Cardozo L, Roberts RG, Thüroff J, Wein AJ. How widespread are the symptoms of an overactive bladder and how are they managed? A population-based prevalence study. BJU Int. 2001;87(9):760-66.

25. Borello-France D, Burgio KL, Goode PS, et al. Adherence to behavioral interventions for stress incontinence: rates, barriers, and predictors. Phys Ther. 2013;93(6):757-73.

26. Ivanova JI, Hayes-Larson E, Sorg RA, Birnbaum HG, Berner T. Healthcare resource use and costs of privately insured patients who switch, discontinue, or persist on anti-muscarinic therapy for overactive bladder. J Med Econ. 2014;17(10):741-50.

27. Boustani M, Campbell N, Munger S, Maidment I, Fox C. Impact of anticholinergics on the aging brain: a review and practical application. Aging Health. 2008;4(3):311-20.
28. Centers for Medicare \& Medicaid Services. 2013 CMS Statistics. 2013. Available at: http://www.cms.gov/Research-Statistics-Data-and-Systems/ Statistics-Trends-and-Reports/CMS-Statistics-Reference-Booklet/Downloads/ CMS_Stats_2013_final.pdf\#tablei2. Accessed July 19, 2016.

29. Truven Health Analytics. Micromedex Online: Redbook. Available at: http://www.micromedexsolutions.com/home/dispatch. Accessed July 19, 2016.

30. Edwards S, Karner C, Trevor N, Barton S, Nherera L. Mirabegron for the treatment of symptoms associated with overactive bladder. STA Report. NIHR HTA Programme Proj. No. 11/138. BMJ Technology Assessment Group. September 1, 2013. Available at: https://www.nice.org.uk/guidance/ ta290/resources/overactive-bladder-mirabegron-evidence-review-groupreport2. Accessed July 19, 2016.

31. Wagg A, Compion G, Fahey A, Siddiqui E. Persistence with prescribed antimuscarinic therapy for overactive bladder: a UK experience. BJU Int. 2012;110(11):1767-74. Available at: http://onlinelibrary.wiley.com/ doi/10.1111/j.1464-410X.2012.11023. Accessed July 19, 2016.

32. Armstrong EP, Malone DC, Bui CN. Cost-effectiveness analysis of anti-muscarinic agents for the treatment of overactive bladder. J Med Econ. 2012;15(Suppl 1):35-44.

33. Avalere Health. Table 4.4. Aggregate hospital payment-to-cost ratios for private payers, Medicare and Medicaid, 1992-2012. Trendwatch Chartbook 2014. American Hospital Association. Washington, DC. 2014. Available at: http://www.aha.org/research/reports/tw/chartbook/2016/table4-4.pdf. Accessed August 3, 2016.

34. Campbell NL, Maidment I, Fox C, Khan B, Boustani MA. The 2012 update to the anticholinergic cognitive burden scale. J Am Geriatr Soc. 2013; 61(Suppl 1):S142-43.

35. Gray SL, Anderson ML, Dublin S, et al. Cumulative use of strong anticholinergics and incident dementia. A prospective cohort study. JAMA Intern Med. 2015;175(3):401-07.

36. Campbell NL, Boustani MA, Lane KA, et al. Use of anticholinergics and the risk of cognitive impairment in an African American population. Neurology. 2010;75(2):152-59. Available at: http://www.ncbi.nlm.nih.gov/ pmc/articles/PMC2905930/. Accessed July 19, 2016.

37. Boustani M, Callahan CM, Unverzagt FW, et al. Implementing a screening and diagnosis program for dementia in primary care. J Gen Intern Med. 2005;20(7):572-77.

38. Cai X, Campbell N, Khan B, Callahan C, Boustani M. Long-term anticholinergic use and the aging brain. Alzheimers Dement. 2013;9(4):377-85. Available at: http://www.ncbi.nlm.nih.gov/pmc/articles/PMC3674201/. Accessed July 19, 2016.

39. Darkow T, Fontes CL, Williamson TE. Costs associated with the management of overactive bladder and related comorbidities. Pharmacotherapy. 2005;25(4):511-19.

40. Fox C, Smith T, Maidment I, et al. Effect of medications with anti-cholinergic properties on cognitive function, delirium, physical function and mortality: a systematic review. Age Ageing. 2014;43(5):604-15. Available at: http:// ageing.oxfordjournals.org/content/43/5/604.long. Accessed July 19, 2016.

41. Fox C, Richardson K, Maidment ID, et al. Anticholinergic medication use and cognitive impairment in the older population: the Medical Research Council Cognitive Function and Ageing Study. J Am Geriatr Soc. 2011;59(8):1477-83. 
42. Khullar V, Amarenco G, Angulo JC, et al. Efficacy and tolerability of mirabegron, a $\beta$ (3)-adrenoceptor agonist, in patients with overactive bladder: results from a randomised European-Australian phase 3 trial. Eur Urol. 2013;63(2):283-95. Available at: http://www.europeanurology.com/article/ S0302-2838(12)01235-3/fulltext/efficacy-and-tolerability-of-mirabegron-ax003b2-sub-3-sub-adrenoceptor-agonist-in-patients-with-overactive-bladderresults-from-a-randomised-european-x02013-australian-phase-3-trial-imgsrc-manager-uploads-europeanurology-com-eur-articles-s0302-283812-01235-3-assets-eulogol-jpg-alt-eulogol. Accessed July 19, 2016.
43. Chapple CR, Kaplan SA, Mitcheson D, et al. Randomized double-blind, active-controlled phase 3 study to assess 12-month safety and efficacy of mirabegron, a $\beta(3)$-adrenoceptor agonist, in overactive bladder. Eur Urol. 2013;63(2):296-305. Available at: http://www.europeanurology.com/ article/S0302-2838(12)01324-3/fulltext/randomized-double-blind-activecontrolled-phase-3-study-to-assess-12-month-safety-and-efficacy-of-mirabegron-a-x003b2-sub-3-sub-adrenoceptor-agonist-in-overactive-bladder. Accessed July 19, 2016

44. Myrbetriq (mirabegron) extended-release tablets, for oral use. Astellas Pharma U.S. Revised December 2015. Available at: http://www.astellas.us/ docs/Myrbetriq_WPI.pdf. Accessed July 19, 2016. 


\section{APPENDIX A Assumptions of Budget Impact Model}

1. All comparators are assumed to be equally efficacious in relieving OAB symptoms.

2. Costs for nonpharmacological $\mathrm{OAB}$ treatments are not included in the model

3. In the primary analysis, the increasing market share for mirabegron comes from other OAB treatments in proportion to their current market shares (Population A)

4. Population B contains patients who are untreated, either due to high ACB or discontinuations due to adverse events. In the secondary analysis, a portion of this population shifts on to mirabegron.

5. The number of patients on each treatment is constant throughout the year.

6. For each given year, the market share of each treatment remains constant.

7. A treatment with lower persistence must have a higher rate of treatment initiation to maintain its market share.

8. The persistence of $\mathrm{OAB}$ treatments after the end of the first month decrease exponentially until they reach the corresponding persistence rate at 12 months (Kaplan-Meier persistence curve takes an exponential decay shape). The treatment discontinuations at 1 month for mirabegron, fesoterodine, darifenacin, solifenacin, oxybutynin, tolterodine IR and ER, and trospium were $25 \%, 55.1 \%, 48 \%, 42 \%, 52 \%, 48 \%, 51 \%$, and $60 \%$, respectively. 30,32 At 12 months, the discontinuations were $55 \%, 82 \%, 82.6 \%, 65 \%, 76.1 \%, 75.9 \%, 71.8 \%$, and $74.1 \%$ for mirabegron, fesoterodine, darifenacin, solifenacin, oxybutynin, tolterodine IR and ER, and trospium, respectively. 30,32

9. Persistence at the end of the first year is maintained in the following years.

10. Comorbidity costs are applied as one-time costs to a population based on the comorbidity rates and treatment market shares.

11. All patients that start a treatment receive a specified number of primary care physician visits (currently l) for that treatment. An additional physician visit is incurred at each medications switch, hence, increasing the physician visit costs for drugs with lower persistence.

12. The plan population is constant over the time horizon of the model.

13. The prevalence of $\mathrm{OAB}$ or the proportion of patients seeking care is constant over the time horizon of the model.

14. Demographic characteristics (age and gender) do not impact dosing, persistence, comorbidity rates, comorbidity costs, or physician visits.

15. The costs of all drug-related adverse effects other than those associated with ACB are negligible and excluded from the model.

16. Annual risks of comorbidities were assumed to be higher in untreated $O A B$ patients than treated patients.

$A C B=$ anticholinergic cognitive burden; $E R=$ extended release; $I R=$ immediate release; $O A B=$ overactive bladder. 
